\title{
Saddle-shaped mitral valve annuloplasty rings improve leaflet coaptation geometry
}

\author{
Morten O. Jensen, PhD, ${ }^{\text {a,b }}$ Henrik Jensen, MD, PhD, ${ }^{a}$ Robert A. Levine, MD, ${ }^{\mathrm{c}}$ Ajit P. Yoganathan, $\mathrm{PhD},{ }^{\mathrm{d}}$ \\ Niels Trolle Andersen, PhD, ${ }^{\mathrm{e}}$ Hans Nygaard, DMSc, ${ }^{\mathrm{a}, \mathrm{b}}$ J. Michael Hasenkam, MD, DMSc, ${ }^{\mathrm{a}}$ and \\ Sten L. Nielsen, MD, PhD, DMSc ${ }^{\mathrm{a}}$
}

\begin{abstract}
Objectives: The mitral valve annulus naturally conforms to a saddle shape in systole. This configuration is believed to put the leaflets into a lower-energy equilibrium with the annulus and subvalvular apparatus. Conventional flat annuloplasty rings restrict posterior leaflet motion, which may result in a "monocusp" valve, affecting valvular stress distribution. It is hypothesized that saddle-shaped annuloplasty rings cause less distortion of the physiologic leaflet geometry than do flat rings.
\end{abstract}

Methods: Twelve pigs were studied in an acute setting with 3-dimensional echocardiography and sonomicrometry before and after implantation of rigid flat $(n=5)$ and saddle-shaped $(n=7)$ annuloplasty rings. The rings were true sized to the annulus with equal anterior-posterior and commissure-commissure circumferential dimensions. The saddle-shaped rings had an annular height to commissural width ratio of $15 \%$.

Results: Saddle-shaped rings maintained both leaflets operational $(P<.01)$. Flat rings made the posterior leaflet immobile and the anterior leaflet aligned flat along the annulus in systole, effectively resulting in monoleaflet function. The average distance from the papillary muscle tips to the posterior annulus decreased by $2.4 \pm 0.4$ $\mathrm{mm}$ after flat ring implantation $(P<.01)$.

Conclusions: Saddle-shaped annuloplasty rings provide better leaflet coaptation geometry than do flat rings by not hoisting the papillary muscles toward the posterior annulus through the commissural chordae, allowing greater leaflet mobility. This entails a potentially beneficial impact on valvular stress distribution that could affect durability of the repaired valve. (J Thorac Cardiovasc Surg 2011;142:697-703)

During the past 20 years, mitral valve (MV) repair has been increasingly preferred over replacement. ${ }^{1}$ As an adjunct procedure, annuloplasty ring implantation is believed

\footnotetext{
From the Department of Cardiothoracic and Vascular Surgery, ${ }^{a}$ Institute of Clinical Medicine, Aarhus University Hospital, Skejby, Aarhus, Denmark; the Department of Biomedical Engineering, ${ }^{\mathrm{b}}$ Engineering College of Aarhus, Aarhus, Denmark; the Massachusetts General Hospital, ${ }^{\mathrm{c}}$ Harvard Medical School, Boston, Mass; the Wallace H. Coulter School of Biomedical Engineering, ${ }^{\text {d }}$ Georgia Institute of Technology and Emory University, Atlanta, Ga; and the Department of Biostatistics, ${ }^{\mathrm{e}}$ Aarhus University, Aarhus, Denmark.

This research project was funded by the Danish Heart Foundation grants \#B248A389-30, \#B248-A946-38, and \#07-4-B248-A1380-22362, the A.P. Møller Foundation for the Advancement of Medical Science, Snedkermester Sophus Jacobsen og hustru Astrid Jacobsens Fond, Hørslev Fonden, Aase og Ejnar Danielsens Fond, The Danish Medical Association Research Fund, Helga og Peter Kornings Fund, Simon Fougner Hartmanns Famile Fond, Jens Anker Andersen Fonden, Købmand Sven Hansen og hustru Ina Hansens Fond, Lykfeldts Legat, Kong Christian den Tiendes Fond, Eva \& Henry Frænkels Mindefond, Dr Poul M. Christiansens \& hustrus fond, Frimodt-Heineke Fonden, and Kirsten Anthonius' Mindelegat. Dr Ajit P. Yoganathan's participation in this research project was funded by the National Heart, Lung, and Blood Institute (NHLBI) grant \#HL 52009. Dr Robert A. Levine's participation was supported by NHLBI grant \#K24 HL67434 as well as grant 07CVD04 from the Leducq Foundation, Paris, France, for the Leducq MITRAL Transatlantic Network.

Disclosures: Authors have nothing to disclose with regard to commercial support.

Received for publication July 28, 2010; revisions received Dec 17, 2010; accepted for publication Jan 10, 2011; available ahead of print Feb 17, 2011.

Address for reprints: Morten Oelgaard Jensen, PhD, Department of Cardiothoracic \&

Vascular Surgery, Aarhus University Hospital, Skejby, 8200 Aarhus N, Denmark

(E-mail: dr.morten.jensen@gmail.com).

$0022-5223 / \$ 36.00$

Copyright (c) 2011 by The American Association for Thoracic Surgery

doi:10.1016/j.jtcvs.2011.01.022
}

to support the repair and increase durability of the operation. $^{2}$

Improved 3-dimensional (3D) visualization techniques such as echocardiography and magnetic resonance imaging have provided new insight into the dynamic behavior of the MV apparatus and improved repair techniques. ${ }^{3}$ The natural shape of the MV annulus changes dynamically throughout the cardiac cycle. It conforms to a saddle shape (hyperbolic paraboloid) in systole and dilates back to a flatter configuration during diastole. ${ }^{4-8}$ This configuration is believed to increase leaflet curvature and put the leaflets into a lowerenergy equilibrium with the annulus and subvalvular apparatus, hereby minimizing stresses in the leaflets and surrounding tissues. ${ }^{6,7,9-12}$ This has prompted a re-evaluation of MV annuloplasty ring designs. ${ }^{5,7,9,13-16}$ In conjunction with annular dynamics, leaflet and chordal geometry plays an important role in the valvular force equilibrium. It has been proposed that the triangular chordal connection between the leaflets, the annulus, and the subvalvular apparatus plays a significant role in MV functionality. ${ }^{17,18}$ Hence, the saddle shape of the mitral annulus is part of a sophisticated geometric construct that is designed to work in concert while minimizing stress on the individual components.

The mechanical properties of conventional annuloplasty rings available today are typically uniformly distributed around the annular circumference, with no or little attention drawn to the natural 3D dynamics of the MV annulus. New 


$$
\begin{aligned}
& \text { Abbreviations and Acronyms } \\
& \text { 3D }=3 \text {-dimensional } \\
& \text { ECG }=\text { electrocardiography } \\
& \text { PM }=\text { papillary muscle } \\
& \text { MV }=\text { mitral valve } \\
& \text { RFAR }=\text { rigid flat annuloplasty ring (group) } \\
& \text { RSAR }= \text { rigid saddle-shaped annuloplasty ring } \\
& \text { (group) }
\end{aligned}
$$

generations, however, of either nonplanar or flexible rings have become available. However, these rings either fix the annulus in a certain 3D configuration or provide insufficient support for the repair.

Annuloplasty ring implantation affects MV leaflet behavior. For example, postannuloplasty monocusp behavior of the anterior leaflet and immobilization of the posterior leaflet of the MV have been described, ${ }^{19,20}$ and recently the influence of ring design on leaflet curvature and functionality has been investigated in vivo. ${ }^{13,20,21}$ However, the underlying mechanism behind improving leaflet curvature is not well understood and the overall positive effect on the MV force balance remains to be answered. Hence, the impact of different mitral annular remodeling by flat and saddleshaped annuloplastry rings on mitral leaflet coaptation geometry in vivo needs to be investigated further.

We hypothesize in this short-term, nonischemic study that true-sized saddle-shaped annuloplasty rings cause less distortion of the physiologic leaflet geometry and coaptation pattern than do true-sized flat rings. The aim was to compare 3D dynamics of leaflets, annulus, and papillary muscles (PMs) between flat and saddle-shaped annuloplasty rings.

\section{MATERIALS AND METHODS}

\section{Surgical Preparation and Sonomicrometry}

Sixteen mixed Yorkshire and Danish Landrace pigs with a body weight of $80 \mathrm{~kg}$ were included in a short-term setup. Three animals were excluded from the rigid flat annuloplasty ring (RFAR) group and 1 was excluded from the rigid saddle-shaped annuloplasty ring (RSAR) group owing to poor ultrasound signal quality. These issues were not caused by factors that are linked to the results in this project (risking a biasing error in the selection process), but simply owing to generic ultrasound quality assessment. All pigs were bred under standard laboratory animal conditions, and the experiment complied with the guidelines from the Danish Inspectorate of Animal Experimentation. The study was approved by this institution. The details of the surgical preparation of porcine animal experimental protocols at our institution have previously been described. ${ }^{22}$ The pigs were humanely killed by injection of $50 \mathrm{~mL}$ pentobarbital directly into the left ventricle.

After establishment of cardiopulmonary bypass and cardioplegic arrest, the MV was exposed through a left atriotomy. Eight sonomicrometry crystals were placed equally spaced in the annulus plane, one on each PM tip, and one in the apex. ${ }^{9}$ The sonomicrometry equipment consisted of 2-mm round crystals with suture loops and a data acquisition system with an external ultrasound transceiver unit and a personal computer with an installed digital circuit board to record the intercrystal distance (Sonometrics Corp, London, Ontario, Canada). The annuloplasty ring sutures were premounted in the circumference of the mitral annulus to facilitate subsequent ring implantation on the beating heart. Sutures and crystal wires were exteriorized through the left atriotomy. The wires from the PM and apex crystals were exteriorized through the apex. The atriotomy was closed, and after 1 hour of reperfusion the animals were weaned from bypass. After hemodynamic stabilization, baseline electrocardiography (ECG), 3D sonomicrometry crystal array coordinates, hemodynamics (pulmonary artery flow, left ventricular pressure, and left atrial pressure), and echocardiographic data were recorded while the animals were intubated and with the chest open.

\section{Annuloplasty Rings}

The mitral annuloplasty rings were designed on the basis of the profile of the D-shaped Carpentier-Edwards Classic annuloplasty ring (Edwards Lifesciences, Irvine, Calif). The flat (RFAR group) and saddle-shaped configuration (RSAR group) were based on the same profile and the RSARs were designed with an annular height to commissural width ratio of $15 \%$. The dimensions of the MV annulus in an 80-kg pig are very similar to the adult human MV annulus, ${ }^{23}$ correlating the Carpentier-Edwards ring size between 30 and 32 . Hence, the rings were true sized to the annulus with equal anterior-posterior and commissure-commissure circumferential dimensions to minimize confounding adverse mechanical effects from undersizing annuloplasty. ${ }^{24,25}$ The rings were built with the use of Rapid Prototyping Technology (DAVINCI Development, Billund, Denmark, and Danish Technological Institute, Aarhus, Denmark). Plastic was chosen as material to minimize artifacts on echocardiographic imaging.

\section{Experimental Protocol}

After baseline recordings (see above), cardiopulmonary bypass was reestablished, and the left atrium was reopened on the beating heart. Each pig was used as its own control. Five pigs received RFARs and 7 received RSARs. The rings were implanted to the annulus using the 8 premounted sutures. The heart was again weaned from cardiopulmonary bypass, and after hemodynamic stabilization, ECG, 3D sonomicrometry crystal array coordinates, and echocardiographic and hemodynamic data were recorded.

\section{Data Acquisition}

Hemodynamics. Left ventricular and left atrial pressures were acquired with Mikro-Tip pressure catheters (SPC-350MR; Millar Instruments, Inc, Houston, Tex). Cardiac output was acquired on the main pulmonary artery location with transit time ultrasound perivascular flow probes (Transonic Systems Inc, Ithaca, NY) and the CardioMed data acquisition system (model 4008; CardioMed A/S, Oslo, Norway). Analog signals from the pressure and flow acquisition systems were acquired with data acquisition hardware (NI9215; National Instruments, Austin, Tex). ECG and hemodynamic data were recorded with custom-designed virtual instrumentation software (LabVIEW version 8.2; National Instruments).

Echocardiography. The 2D biplane echocardiographic recordings in a parasternal long-axis view was acquired by epicardial echocardiography using an ultrasound scanner (Vivid 7; GE Vingmed Ultrasound, Horten, Norway) equipped with a $3 \mathrm{D}$ matrix-probe $3 \mathrm{~V}$ with a frequency range of 2 to $5 \mathrm{MHz}$. Measurements were performed before and after implantation of the rings to assess the angles, coaptation tenting height (Figure 1), area between the annular plane and the leaflets (coaptation tenting area), and leaflet curvature (Figure 2). The sonomicrometry system was inactivated during echocardiographic imaging. Utilizing the biplane ultrasound probe and software ensured that leaflet measurements were obtained throughout the MV septal-lateral axis of symmetry (center of the fibrous trigones), ensuring that the septal-lateral axis did not shift during acquisition of the cardiac cycle. This consistency was verified by comparing the 

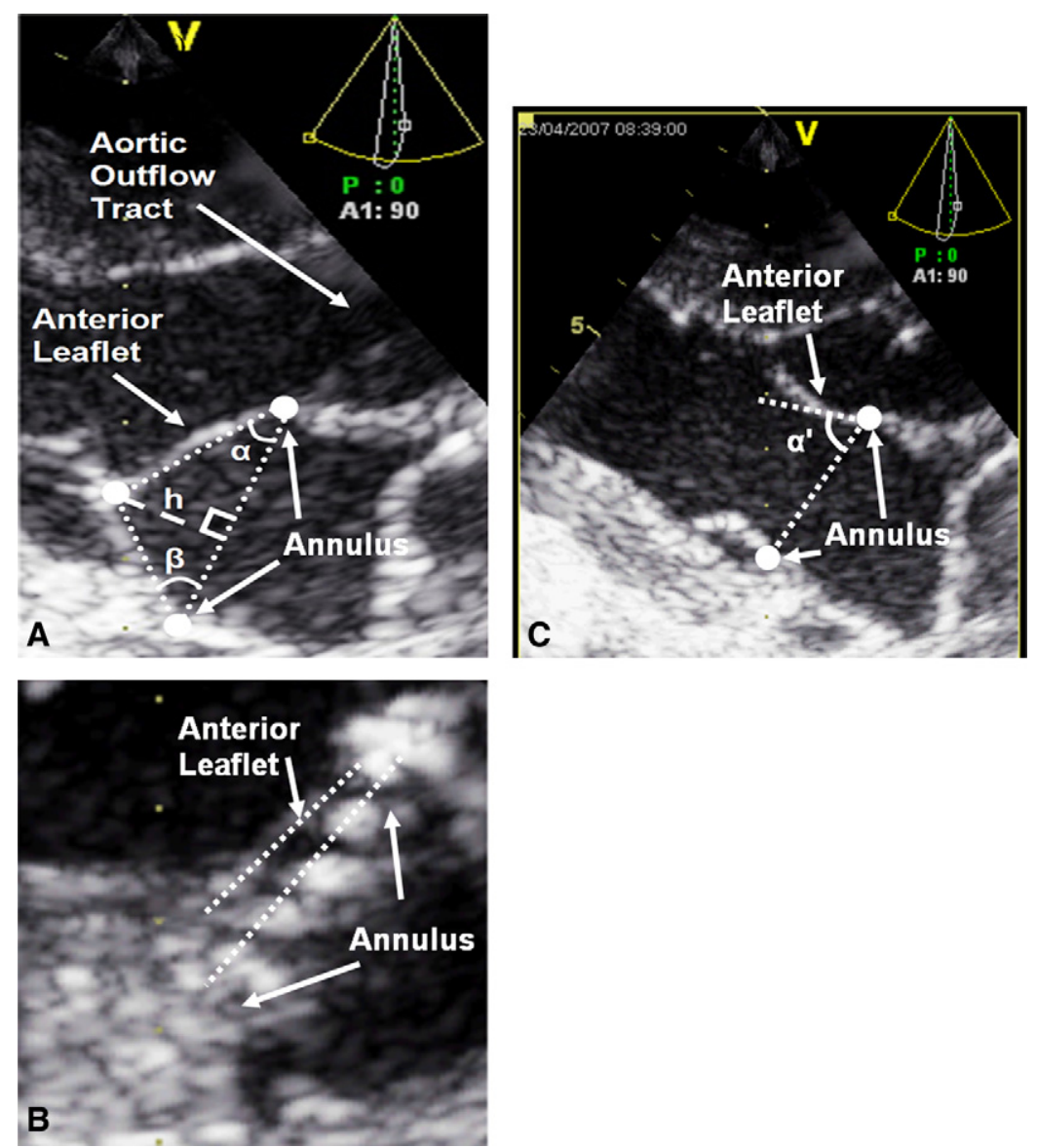

FIGURE 1. Ultrasound images from the biplane echocardiographic system with indication of mitral leaflet geometry analysis landmarks. A, Example of mid-systole before ring implantation. $\alpha$, Anterior leaflet systolic coaptation angle (between anterior leaflet and mitral annulus); $\beta$, coaptation angle of posterior leaflet; $h$, coaptation tenting height. B, Mid-systole with a flat ring implanted. The anterior leaflet is aligned flat with the annulus. $\mathrm{C}$, Example of mid-diastole leaflet configuration before ring implantation; $\alpha^{\prime}$, Anterior leaflet diastolic opening angle.

diastolic and systolic septal-lateral distance measured by sonomicrometry and ultrasound. Digital cineloop images along with the ECG were acquired with suspended respiration and downloaded to a computer for offline analysis facilitated by commercially available software (see below).

\section{Data Analysis}

Hemodynamics. For offline analysis, all analog signals were initially pre-processed with a 10 heart cycle ensemble average. Mid-systole and mid-diastole were defined as center points between maximum rate of rise and maximum rate of fall of left ventricular pressure. Pressures are reported at mid-systole. Sonomicrometry and biplane echocardiographic measurements are reported at mid-diastole and mid-systole. Cardiac output was calculated by integrating the flow measurement through 1 cardiac cycle, which was defined as the time from ECG QRS peak-to-peak. ECG and hemodynamic parameters were used for synchronization between the sonomicrometry and the LabVIEW data acquisition systems. Hemodynamic analysis was performed with dedicated software programs developed with LabVIEW version 8.2 (National Instruments)

Echocardiography. MV geometry was analyzed in mid-systole and mid-diastole as defined above. The line of the mitral annular hinge points was established as a reference frame in baseline echocardiography. Annulus location was clearly identified with the ultrasound echoes from the sonomicrometry crystals and the annuloplasty rings. Figures 1 and 2 show measurements of MV leaflet coaptation geometry. Anterior leaflet curvature and circumcircle radius measurements were performed as described in Figure 2, $B$ and $C$. Leaflet geometry measurements were performed on dedicated software (EchoPAC PC Dimension version 6.1.2, GE Vingmed Ultrasound)

\section{Statistical Analysis}

All data are reported as mean \pm the standard deviation. Differences in echocardiographic and sonomicrometric measurements between midsystole and mid-diastole and hemodynamic parameters before and after ring insertion were tested by paired $t$ tests using the STATA statistical calculation software (StataCorp LP, College Station, Tex). The comparison of the systolic leaflet geometry measurements before and after implantation of flat and saddle-shaped rings is performed with an unpaired $t$ test of data obtained as an average of measurements from 2 independent observers. Measurements of the systolic leaflet geometry after flat ring implantation resulted in data that rendered consistent flat anterior leaflet geometry aligned with the flat annuloplasty ring. Hence, the comparison with this data set before and after ring implantation is performed with the Wilcoxon rank sum (Mann-Whitney) nonparametric method.

\section{RESULTS}

Hemodynamic data are summarized in Table 1 . Crossclamp/cardiopulmonary bypass time was $60 \pm 12 / 126 \pm 20$ 


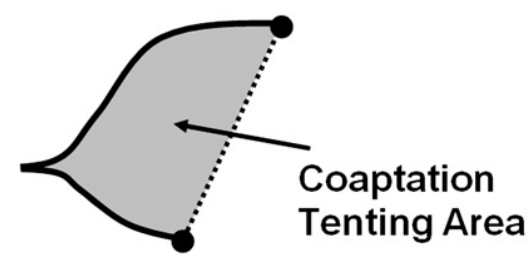

A
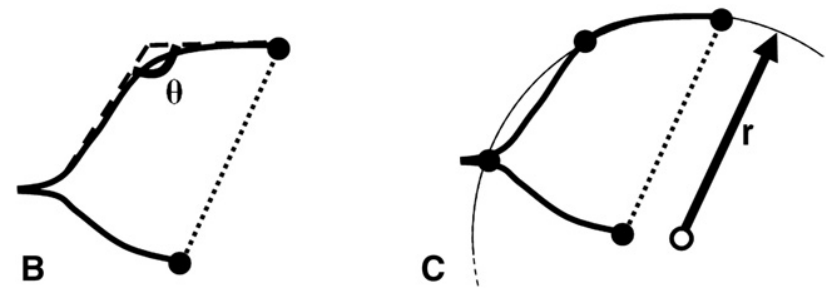

FIGURE 2. Schematic indication of systolic mitral leaflet geometry analysis landmarks. A, Mitral valve coaptation tenting area. B, Anterior leaflet systolic curvature angle $(\theta)$. C, Radius of anterior leaflet systolic circumscribed circle $(r)$.

minutes during sonomicrometry crystal implantation and 0 minutes during ring implantation (beating heart with premounted sutures). Sonomicrometry data verified that the ratio of systolic annular height to commissural width before ring implantation was not statistically significantly different from the ratio of annular height to commissural width of the custom-designed saddle-shaped rings of $15 \%(P>.1$, Table 2). Analysis of annular dimensions with sonomicrometry is summarized before and after flat and saddle-shaped ring implantation (Table 2). Coordinate free analysis of annular dimensions after ring implantation shows that the anterior-posterior (septal-lateral) distance was $19 \pm 2 \mathrm{~mm}$ and $21 \pm 2 \mathrm{~mm}$ for the flat and saddle-shaped rings, respectively $(P=.33)$, whereas the commissure-commissure distance was $29 \pm 2 \mathrm{~mm}$ and $30 \pm 3 \mathrm{~mm}$ after flat and saddleshaped ring implantation, respectively $(P=.19)$. MV systolic coaptation geometric measurements are summarized in Table 3. See Figures 1 and 2 for definitions. Angular motion $\left(\Delta \alpha=\alpha^{\prime}-\alpha\right.$, Figure 1) of the anterior leaflet from diastole

TABLE 1. Hemodynamic measurements

\begin{tabular}{ccccc}
\hline Ring type & $\mathbf{n}$ & Heart rate $(\mathbf{b p m})$ & LVP $(\mathbf{m m} \mathbf{H g})$ & CO $(\mathbf{L} / \mathbf{m i n})$ \\
\hline Group 1: RSAR & & & & \\
$\quad$ Before ring & 7 & $118 \pm 15$ & $109 \pm 31$ & $6.4 \pm 1.7$ \\
With ring & 7 & $123 \pm 23$ & $97 \pm 43$ & $5.3 \pm 1.8$ \\
Group 2: RFAR & & & & \\
Before ring & 5 & $101 \pm 20$ & $125 \pm 39$ & $4.8 \pm 1.8$ \\
With ring & 5 & $127 \pm 20^{*}$ & $98 \pm 16$ & $5.8 \pm 2.2$ \\
\hline
\end{tabular}

Data are stated as mean \pm standard deviation. $n$, Sample size; bpm, beats/min; $L V P$, mid-systolic left ventricular pressure; $C O$, cardiac output; $R S A R$, rigid saddle annuloplasty ring; RFAR, rigid flat annuloplasty ring. ${ }^{*}$ The heart rate increased after flat ring implantation $(P=.0097)$. No statistically significant difference was observed before and after ring implantation for any of the other hemodynamic parameters $(P>.05)$.
TABLE 2. Annular dimensions with sonomicrometry before and after flat and saddle-shaped ring implantation

\begin{tabular}{llccc}
\hline \multicolumn{1}{c}{ Ring type } & $\mathbf{n}$ & ANT-POST & COM-COM & AHCWR \\
\hline $\begin{array}{l}\text { Group 1: RSAR } \\
\text { Mid-systole }\end{array}$ & & & & \\
$\quad$ Before ring & 7 & $23 \pm 4$ & $32 \pm 2$ & $13.2 \pm 2.8$ \\
$\quad$ With ring & 7 & $21 \pm 2$ & $30 \pm 2$ & $14.5 \pm 5.2$ \\
Mid-diastole & & & & \\
$\quad$ Before ring & 7 & $24 \pm 2$ & $32 \pm 4$ & $10.1 \pm 4.6$ \\
$\quad$ With ring & 7 & $21 \pm 4$ & $30 \pm 2$ & $17.1 \pm 5.9^{*}$ \\
Group 2: RFAR & & & & \\
Mid-systole & & & & \\
$\quad$ Before ring & 5 & $23 \pm 4$ & $31 \pm 6$ & $15.4 \pm 3.3$ \\
$\quad$ With ring & 5 & $19 \pm 3$ & $27 \pm 4$ & $7.7 \pm 5.1^{*}$ \\
Mid-diastole & & & & \\
$\quad$ Before ring & 5 & $27 \pm 3$ & $35 \pm 4$ & $8.8 \pm 4.6$ \\
$\quad$ With ring & 5 & $19 \pm 2 *$ & $29 \pm 2$ & $10.3 \pm 6.6$ \\
\hline
\end{tabular}

Data are stated as mean \pm standard deviation. $n$, Sample size; ANT-POST, distance between the center of the anterior annulus (between the trigones) and the posterior annulus (center of P2 segment); COM-COM, distance between the commissural areas; $A H C W R$, annular height to commissural width ratio; $R S A R$, rigid saddle annuloplasty ring; RFAR, rigid flat annuloplasty ring. *Statistically significant difference between ring versus no ring groups $(P<.05)$.

to systole after ring implantation was dictated by the systolic angle of the anterior leaflet, inasmuch as no statistically significant differences was found for $\alpha^{\prime}$ before and after flat and saddle-shaped ring implantation (Table 3). The hypothesis that the angle between the annulus and the anterior leaflet during diastole before and after flat and saddle-shaped annuloplasty are not equal to each other cannot be rejected; so there is some evidence that this angle remained unchanged after annuloplasty (flat or saddle-shaped; $P>0.1$; Figure 1, $C)$. A convex curvature of the anterior leaflet toward the left ventricular apex in systole was detectable in 8 of 12 pigs before ring implantation (systolic curvature bending angle $\theta=154^{\circ} \pm 2^{\circ}$; circumscribed circle radius: $27 \pm 3 \mathrm{~mm}$ [n $=8$ ], see Figure 2, $B$ and $C$, for definitions). The anterior leaflet curvature was not present after ring implantation of flat and saddle-shaped rings $(\theta=180 ; P<.01)$.

Sonomicrometry data yielded that flat ring implantation decreased the average systolic distance from the posterior and anterior PMs to the posterior annulus by $2.4 \pm 0.4$ $\mathrm{mm}$. Saddle-shaped ring implantation decreased the average systolic distance from the PMs to the posterior annulus by $1.0 \pm 0.3 \mathrm{~mm}$, which was statistically significantly less than for the flat rings $(P<.01)$

\section{DISCUSSION}

The rings tested in this study are based on the classic stiff D-shaped Carpentier-Edwards ring and a saddle-shaped modification thereof. The application of the same template for the 2 rings in this study made it possible to isolate the impact of saddle shape, while the remaining geometric factors are kept constant for mitral annulus and leaflet 
TABLE 3. Summary of systolic geometry measurements

\begin{tabular}{lcccccc}
\hline \multicolumn{1}{c}{ Ring type } & $\mathbf{n}$ & $\mathbf{h}(\mathbf{m m})$ & $\mathbf{A}\left(\mathbf{m m}^{\mathbf{2}}\right)$ & $\boldsymbol{\alpha}\left(^{\circ}\right)$ & $\boldsymbol{\alpha}^{\prime}\left(^{\circ}\right)$ & $\boldsymbol{\beta}\left(^{\circ}\right)$ \\
\hline Group 1, RSAR & & & & & & \\
Before ring & 7 & $12 \pm 2$ & $187 \pm 39$ & $30 \pm 5$ & $71 \pm 5$ & $40 \pm 6$ \\
With ring & 7 & $8 \pm 2^{*}$ & $76 \pm 9^{*}$ & $24 \pm 7$ & $75 \pm 15$ & $52 \pm 8$ \\
Group 2, RFAR & & & & & & \\
Before ring & 5 & $13 \pm 3$ & $220 \pm 50$ & $35 \pm 6$ & $70 \pm 17$ & $34 \pm 9$ \\
With ring & 5 & $<1^{*}, \dagger$ & $<1^{*}, \dagger$ & $<1^{*}, \dagger$ & $59 \pm 5$ & $90^{*}, \dagger$ \\
\hline
\end{tabular}

Data stated as mean \pm standard deviation. See Figures 1 and 2 for definition of systolic geometry measurements. $n$, Sample size; $h$, coaptation tenting height; $A$, coaptation tenting area; $\alpha$, anterior leaflet coaptation angle; $\alpha^{\prime}$, anterior leaflet diastolic opening angle; $\beta$, posterior leaflet coaptation angle; $R S A R$, rigid saddle annuloplasty ring; $R F A R$, rigid flat annuloplasty ring. For the flat ring, " $<1$ " means that no anterior leaflet coaptation angle could be observed, also rendering the height and area less than 1. Similarly, as $\alpha$ approaches $0^{\circ}, \beta$ approaches $90^{\circ}$. $*$ Statistically significant difference between ring versus no ring groups $(P<.01)$. $†$ Statistically significant difference between flat ring versus saddle-shaped ring groups $(P<.01)$

dynamics. The reason to use rigid annuloplasty rings in the present study was to evaluate the impact of a well-defined systolic shape on annular and leaflet dynamics. Evaluating the influence of other ring designs and repair techniques and their impact on annulus and leaflet geometry is important as well. For example, improvement of leaflet mobility and maintaining natural annular and subvalvular geometry after annuloplasty may be accomplished by techniques such as Paneth suture, using complete or partial flexible annuloplasty rings, or posterior mitral leaflet extension. ${ }^{5,26,27}$ However, the present data can serve as external references (from rigid flat [diastolic frame] to rigid saddle shape [systolic frame]) in which a wide spectrum of commercially available annuloplasty rings can be tested.

Saddle-shaped rings preserved motion of both MV leaflets, although the coaptation angle, coaptation tenting area, and coaptation tenting height of the anterior leaflet relative to the annular plane decreased. After flat ring implantation, the posterior leaflet became immobile and the anterior leaflet aligned flat along the annulus in systole. Hence, the results from this study show that saddleshaped annuloplasty rings provide better leaflet coaptation geometry than flat rings. Saddle-shaped rings may thus have a potentially beneficial impact on valvular stress distribution and may lead to better durability of MV repair.

Recent findings with true-sized modern annuloplasty ring designs conclude that posterior leaflet motion is maintained, ${ }^{15}$ except the Edwards IMR ETlogix and the Edwards GeoForm (Edwards Lifesciences). All other rings in the study by Bothe and colleagues ${ }^{15}$ have certain degrees of saddle-shaped outline (anterior alone, full circumferential, or fully flexible), which may facilitate less adverse posterior leaflet dynamics. Hence, these results are in agreement with the findings presented here.

It has been shown that alteration of hemodynamic conditions do not affect leaflet curvature significantly. ${ }^{28}$ Similarly, in this study, except for heart rate after flat ring implantation, Table 1 shows that no statistically significant difference in hemodynamic parameters was observed before and after ring implantation. The heart rate increase of $26 \%$ after flat ring implantation can be a result of many factors that do not have any impact on the reported mid-systolic leaflet coaptation geometry. Similarly, the fact that cardiac output increases by $21 \%$ after flat ring implantation (not statistically significant) and drops by $17 \%$ after saddle-shaped ring implantation (not statistically significant) is not due to the difference in annuloplasty ring shape and does not have any impact on the reported systolic leaflet coaptation geometry.

It has previously been verified in animal experimentation as well as medical imaging of human subjects that the native MV annulus follows the flat ring configuration in diastole and the $15 \%$ saddle-shaped ring $3 \mathrm{D}$ configuration in systole with respect to annular height to commissural width ratio. ${ }^{4-7,9,29}$ In the annular plane, there was no statistically significant difference between the anterior-posterior and commissurecommissure dimensions after flat and the saddle-shaped ring implantation (Table 2). Hence, in the annular plane, the attachment of the annular structures to the 2 different rigid annuloplasty rings maintained the systolic anteriorposterior and commissural-commissural dimensions. This shows that the rings were not downsizing the annulus in systole. However, the diastolic measurement of the anteriorposterior distance was decreased after RFAR implantation (Table 2). This may have caused an obstruction of forward flow through the MV, although this was not identified as statistically significantly present when observing the cardiac output measurements after RFAR implantation. In addition, it is important to note that implanting the ring on the beating heart with the same sutures used for sonomicrometry crystal implantation may cause these crystals to relocate or shift slightly, which is shown to not be statistically significant in Table 2.

A potential mechanism for the restrictive motion of the posterior leaflet after annuloplasty can be interpreted as follows: It has been shown that true-sized annuloplasty rings may relocate the posterior annulus toward the center of the valve orifice, closer to the coaptation zone, while hoisting it relative to the PM tips. ${ }^{20}$ This holds true for both saddle-shaped and flat annuloplasty rings. Hence, leaflets will be affected even with true-sized saddle-shaped annuloplasty rings, as were used in this study. Accordingly, the posterior leaflet is retracted posteriorly and acts as a door sill to the anterior leaflet, freezing the posterior leaflet. ${ }^{19,20}$ This effect is most predominant in the flat stiff ring, as illustrated in Figure 3, with monocusp behavior of the anterior leaflet, closing flat along the annulus. ${ }^{20}$ However, it has been shown that no adverse apically directed systolic force distribution is seen in saddle-shaped rings; thus an adverse circumferential force distribution in both the flat and the saddle-shaped rings may be present, which we are in the process of investigating. 
Flat Ring

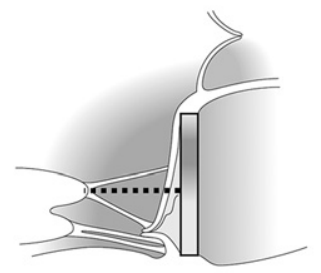

A

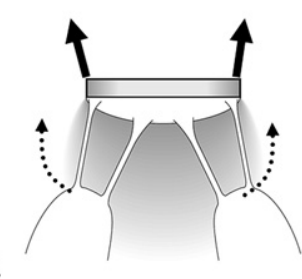

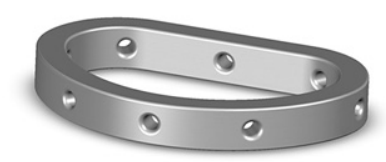

Saddle Shaped Ring
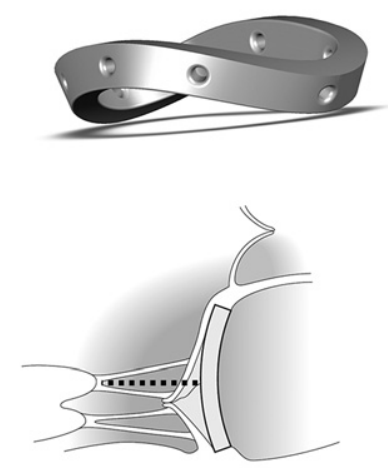

B

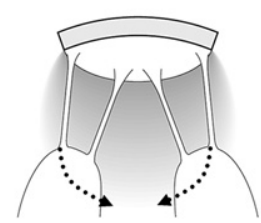

FIGURE 3. Potential mechanism for altered mitral valve leaflet configuration with (A) flat and (B) saddle-shaped annuloplasty rings from a lateral view (top figures) and an anterior view (bottom figures). The flat annuloplasty ring may hoist the papillary muscles laterally through the commissural chords (illustrated by dotted lines in the top figures). The saddle-shaped ring maintained the medial alignment of the papillary muscles to facilitate proper leaflet coaptation.

Furthermore, the flat annuloplasty rings hoist the PMs laterally through the commissural chords (Figure 3, A). This concept is supported by the fact that the decrease in distance from PMs to the posterior annulus and restrictive motion of the posterior leaflet was most pronounced after RFAR implantation. The altered MV coaptation geometry from flat annuloplasty results in a redistribution of the force and strain balance on the mitral leaflets, the annuloplasty rings, and the chordal distribution as dictated by He's triangle. ${ }^{9,17,18,29}$ Higher curvature and lower radius of circumscribed circle of the anterior leaflet is considered to minimize stresses in the leaflets and surrounding tissues according to Laplace's law. ${ }^{6,711,12}$ Hence, the reduced anterior leaflet curvature along with covering most of the mitral orifice after ring annuloplasty as observed in this study causes the anterior leaflet as well as the strut chordae to be subjected to increased stress and load. This concept has been confirmed by in vitro observations. ${ }^{12}$ PM relocation toward the annulus through the commissural chords to facilitate better closure should not be considered a beneficial effect of flat annuloplasty. Relieving excessive leaflet tethering in the chronic ischemic situation with indirect relocation methods as described in the literature ${ }^{30,31}$ should be combined with saddle-shaped annuloplasty to avoid adverse leaflet curvature as much as possible.

\section{Limitations}

Decreased leaflet curvature is a widely known result from chronic ischemic mitral regurgitation, ${ }^{32}$ which may be corrected by appropriate annuloplasty ring shape and flexibility. However, the impact of flat and saddle-shaped annuloplasty on leaflet curvature in the ischemic situation might not be extrapolated from this study. This study was performed in pigs with normal, delicate MVs that do not have excess tissue, which needs to be confirmed as applicable to humans with MV disease. Inasmuch as annulus dynamics are significantly altered with dilated, ischemic heart disease, conforming to a more flat configuration throughout the cardiac cycle, the results from this study might have most clinical relevance in nonischemic degenerative MV repair with annuloplasty performed as an adjunct procedure. In addition, clinical practice experiences that posterior leaflet mobility is also restricted in many patients just by suturing of the leaflet if resection is performed.

\section{CONCLUSIONS}

In this short-term, in vivo experimental model, stiff saddle-shaped annuloplasty rings resulted in less distortion of the physiologic MV leaflet geometry than did flat rings. An annuloplasty ring design that is true-sized to the annulus, which allows the annulus to conform to a saddle in systole while providing sufficient support at the annular plane to facilitate proper healing of the repair, entails a potentially beneficial impact on valvular stress distribution that could affect durability of the repaired valve. Future perspectives, which are a topic of several current research projects in our group, involve investigating whether the same behavior is seen with annuloplasty and PM relocation closer to the anterior annulus.

\section{References}

1. Reul RM, Cohn LH. Mitral valve reconstruction for mitral insufficiency. Prog Cardiovasc Dis. 1997;39:567-99.

2. Gillinov AM, Cosgrove DM, Blackstone EH, Diaz R, Arnold JH, Lytle BW, et al. Durability of mitral valve repair for degenerative disease. $J$ Thorac Cardiovasc Surg. 1998;116:734-43.

3. Grewal J, Suri R, Mankad S, Tanaka A, Mahoney DW, Schaff HV, et al. Mitral annular dynamics in myxomatous valve disease: new insights with real-time 3-dimensional echocardiography. Circulation. 2010;121:1423-31.

4. Levine RA, Handschumacher MD, Sanfilippo AJ, Hagege AA, Harrigan P, Marshall JE, et al. Three-dimensional echocardiographic reconstruction of the mitral valve, with implications for the diagnosis of mitral valve prolapse. Circulation. 1989;80:589-98.

5. Timek TA, Glasson JR, Lai DT, Liang D, Daughters GT, Ingels NB Jr, et al. Annular height-to-commissural width ratio of annulolasty rings in vivo. Circulation. 2005;112(9 Suppl):I423-8.

6. Salgo IS, Gorman JH III, Gorman RC, Jackson BM, Bowen FW, Plappert T, et al. Effect of annular shape on leaflet curvature in reducing mitral leaflet stress. Circulation. 2002;106:711-7.

7. Kunzelman KS, Reimink MS, Cochran RP. Flexible versus rigid ring annuloplasty for mitral valve annular dilatation: a finite element model. J Heart Valve Dis. 1998;7:108-16.

8. Glasson JR, Komeda MK, Daughters GT, Niczyporuk MA, Bolger AF, Ingels NB, et al. Three-dimensional regional dynamics of the normal mitral anulus during left ventricular ejection. J Thorac Cardiovasc Surg. 1996;111:574-85. 
9. Jensen MO, Jensen H, Smerup M, Levine RA, Yoganathan AP, Nygaard H, et al. Saddle-shaped mitral valve annuloplasty rings experience lower forces compared with flat rings. Circulation. 2008;118(14 Suppl):S250-5.

10. Jimenez JH, Liou SW, Padala M, He Z, Sacks M, Gorman RC, et al. A saddleshaped annulus reduces systolic strain on the central region of the mitral valve anterior leaflet. J Thorac Cardiovasc Surg. 2007;134:1562-8.

11. Arts T, Meerbaum S, Reneman R, Corday E. Stresses in the closed mitral valve: a model study. J Biomech. 1983;16:539-47.

12. Jimenez JH, Soerensen DD, He Z, He S, Yoganathan AP. Effects of a saddle shaped annulus on mitral valve function and chordal force distribution: an in vitro study. Ann Biomed Eng. 2003;31:1171-81.

13. Ryan LP, Jackson BM, Hamamoto H, Eperjesi TJ, Plappert TJ, St John-Sutton M, et al. The influence of annuloplasty ring geometry on mitral leaflet curvature. Ann Thorac Surg. 2008;86:749-60.

14. Caimmi PP, Diterlizzi M, Grossini E, Kapetanakis EI, Gavinelli M, Carriero A, et al. Impact of prosthetic mitral rings on aortomitral apparatus function: a cardiac magnetic resonance imaging study. Ann Thorac Surg. 2009;88:740-4.

15. Bothe W, Kvitting JP, Swanson JC, Goktepe S, Vo KN, Ingels NB, et al. How do annuloplasty rings affect mitral leaflet dynamic motion? Eur J Cardiothorac Surg. 2010;38:340-9.

16. Sacks MS, He Z, Baijens L, Wanant S, Shah P, Sugimoto H, et al. Surface strains in the anterior leaflet of the functioning mitral valve. Ann Biomed Eng. 2002;30: 1281-90.

17. He S, Weston MW, Lemmon J, Jensen M, Levine RA, Yoganathan AP. Geometric distribution of chordae tendineae: an important anatomic feature in mitral valve function. J Heart Valve Dis. 2000;9:495-501

18. Lai DT, Tibayan FA, Timek TA, Liang D, Daughters GT, Ingels NB Jr, et al. Three-dimensional in-vivo dimensions of 'He's triangle' during acute left ventricular ischemia. J Heart Valve Dis. 2001;10:767-73.

19. Kuwahara E, Otsuji Y, Iguro Y, Ueno T, Zhu F, Mizukami N, et al. Mechanism of recurrent/persistent ischemic/functional mitral regurgitation in the chronic phase after surgical annuloplasty: importance of augmented posterior leaflet tethering. Circulation. 2006;114(1 Suppl):I529-34.

20. Green GR, Dagum P, Glasson JR, Nistal JF, Daughters GT, Ingels NB Jr, et al. Restricted posterior leaflet motion after mitral ring annuloplasty. Ann Thorac Surg. 1999;68:2100-6
21. Goktepe S, Bothe W, Kvitting JP, Swanson JC, Ingels NB, Miller DC, et al. An terior mitral leaflet curvature in the beating ovine heart: a case study using videofluoroscopic markers and subdivision surfaces. Biomech Model Mechanobiol. 2010;9:281-93.

22. Nielsen SL, Hansen SB, Nielsen KO, Nygaard H, Paulsen PK, Hasenkam JM Imbalanced chordal force distribution causes acute ischemic mitral regurgitation mechanistic insights from chordae tendineae force measurements in pigs J Thorac Cardiovasc Surg. 2005;129:525-31.

23. Kunzelman KS, Cochran RP, Verrier ED, Eberhart RC. Anatomic basis for mitral valve modelling. J Heart Valve Dis. 1994;3:491-6.

24. Lee KS, Stewart WJ, Lever HM, Underwood PL, Cosgrove DM. Mechanism of outflow tract obstruction causing failed mitral valve repair. Anterior displacement of leaflet coaptation. Circulation. 1993;88(5 Pt 2):II24-9.

25. Cheng A, Nguyen TC, Malinowski M, Liang D, Daughters GT, Ingels NB Jr, et al. Effects of undersized mitral annuloplasty on regional transmural left ventricular wall strains and wall thickening mechanisms. Circulation. 2006;114(1 Suppl):I600-9.

26. Tibayan FA, Rodriguez F, Liang D, Daughters GT, Ingels NB Jr, Miller DC. Paneth suture annuloplasty abolishes acute ischemic mitral regurgitation but preserves annular and leaflet dynamics. Circulation. 2003;108(Suppl 1):II128-33.

27. Tibayan FA, Rodriguez F, Langer F, Liang D, Daughters GT, Ingels NB, et al. Mitral suture annuloplasty corrects both annular and subvalvular geometry in acute ischemic mitral regurgitation. J Heart Valve Dis. 2004;13:414-20.

28. Sakamoto H, Parish LM, Hamamoto H, Enomoto Y, Zeeshan A, Plappert T, et al. Effects of hemodynamic alterations on anterior mitral leaflet curvature during systole. J Thorac Cardiovasc Surg. 2006;132:1414-9.

29. Jensen MO, Jensen H, Nielsen SL, Smerup M, Johansen P, Yoganathan AP, et al What forces act on a flat rigid mitral annuloplasty ring? J Heart Valve Dis. 2008 17:267-75.

30. Hung J, Guerrero JL, Handschumacher MD, Supple G, Sullivan S, Levine RA. Reverse ventricular remodeling reduces ischemic mitral regurgitation: echoguided device application in the beating heart. Circulation. 2002;106:2594-600

31. Kron IL, Green GR, Cope JT. Surgical relocation of the posterior papillary muscle in chronic ischemic mitral regurgitation. Ann Thorac Surg. 2002;74:600-1.

32. Tibayan FA, Rodriguez F, Langer F, Zasio MK, Bailey L, Liang D, et al. Increases in mitral leaflet radii of curvature with chronic ischemic mitral regurgitation. J Heart Valve Dis. 2004;13:772-8. 